\title{
Article \\ Conscientiousness in Pilots Correlates with Electrodermal Stability: Study on Simulated Flights under Social Stress
}

\author{
Antonio R. Hidalgo-Muñoz ${ }^{1, *}$, Damien Mouratille ${ }^{1,2}$, Radouane El-Yagoubi ${ }^{1}$, Yves Rouillard ${ }^{2}$, \\ Nadine Matton ${ }^{1,2} \mathbb{D}$ and Mickaël Causse ${ }^{3}$ \\ 1 CLLE, CNRS, Faculty of Psychology, University of Toulouse II, 5 Allées Antonio Machado, \\ 31058 Toulouse, France; damien.mouratille@enac.fr (D.M.); radouane.el-yagoubi@univ-tlse2.fr (R.E.-Y.); \\ nadine.matton@enac.fr (N.M.) \\ 2 École Nationale de l'Aviation Civile, 7 Édouard-Belin, 31055 Toulouse, France; yves.rouillard@enac.fr \\ 3 Institut Supérieur de l'Aéronautique et de l'Espace, 10 Édouard-Belin, 31055 Toulouse, France; \\ mickael.causse@isae-supaero.fr \\ * Correspondence: antonio.hidalgo-munoz@univ-tlse2.fr
}

Citation: Hidalgo-Muñoz, A.R.; Mouratille, D.; El-Yagoubi, R.; Rouillard, Y.; Matton, N.; Causse, M. Conscientiousness in Pilots Correlates with Electrodermal Stability: Study on Simulated Flights under Social Stress. Safety 2021, 7, 49. https:// doi.org/10.3390/safety7020049

Academic Editor: Tom Brijs

Received: 12 March 2021

Accepted: 11 June 2021

Published: 18 June 2021

Publisher's Note: MDPI stays neutral with regard to jurisdictional claims in published maps and institutional affiliations.

Copyright: () 2021 by the authors. Licensee MDPI, Basel, Switzerland. This article is an open access article distributed under the terms and conditions of the Creative Commons Attribution (CC BY) license (https:// creativecommons.org/licenses/by/ $4.0 /)$.

\begin{abstract}
For pilots, the capacity to cope with anxiety is crucial during a flight since they may be confronted with stressful situations. According to the Big Five Inventory, this capacity can be modulated by two important personality traits: conscientiousness and neuroticism. The former would be related to concentration skills and the latter to the attention bias towards anxiety-provoking stimuli. Given the current development of monitoring systems for detecting the users' state, which can be incorporated into cockpits, it is desirable to estimate their robustness to inter-individual personality differences. Indeed, several emotion recognition methods are based on physiological responses that can be modulated by specific personality profiles. The personality traits of twenty pilots were assessed. Afterwards, they performed two consecutive simulated flights without and with induced social stress while electrodermal activity was measured. Their subjective anxiety was assessed before the second flight, prior to the stress-induced condition. The results showed that higher scores in neuroticism correlated positively with cognitive and somatic anxiety. Moreover, under social stress, higher scores in conscientiousness correlated positively with electrodermal stability, i.e., a lower number of skin conductance responses. These results on both self-reported and physiological responses are in favor of the integration of personality differences into pilots' state monitoring.
\end{abstract}

Keywords: anxiety; aviation; conscientiousness; electrodermal activity; flight; neuroticism; personality; skin conductance; stress

\section{Introduction}

Current research in Human Factors shows an increasing interest in developing tailored systems able to determine the affective states of pilots in order to estimate whether they will be able to guarantee safety and to cope with stressful and highly cognitive demanding flying situations [1]. Hence, the integration of emotion recognition techniques into the cockpit is highly desirable not only from a scientific point of view but also for operational safety purposes. However, the consideration of user personality for customizing and adapting the sensitivity of this kind of technology has been scarcely considered to date. The present study aims to examine the impact of pilot personality on self-reported anxiety and on a relevant physiological measure, the skin conductance response (SCR), which can be cost-effectively incorporated into such systems, while performing a flight simulation task under pressure.

Based on the Big Five Inventory (BFI) [2], several studies have shown that pilots tend to present a personality characterized by low neuroticism and high conscientiousness levels in comparison to the general population [3]. This specific combination of low neuroticism and high conscientiousness constitutes a personality style of impulse control defined as 
directed, which corresponds to individuals who have a clear sense of their own objectives and have the capacity to work to achieve them under complex conditions, overcoming obstacles and frustrations successfully [4]. According to a different classification presented in [5], the same combination of these neuroticism and conscientiousness levels is linked to entrepreneur or sceptic personalities, with the two differing in their extraversion level.

In any case, most studies agree in pointing out the tight relation of neuroticism and conscientiousness to the capacity of emotional regulation and concentration, respectively. These are two essential characteristics required in pilots. Indeed, [6] showed that higher neuroticism is associated with a higher level of stress, anxiety or shame, and correlates negatively with coping ability. In [7], several models are proposed where the question about the relationships between neuroticism and anxiety is still open. In contrast, conscientiousness shows the opposite correlations to neuroticism concerning stress level and coping ability. Regarding cognitive skills, in [8], the impact of these two personality traits on training during single and dual cognitive tasks (specifically N-back tasks) was analyzed. The authors showed that high neuroticism correlates with a lower efficiency in training, whereas conscientiousness is linked to more enjoyment in training and overall better performance. Furthermore, [9] found that conscientiousness is linked to self-oriented perfectionism while neuroticism was more linked to socially prescribed perfectionism. These findings suggest the relevance of emphasizing these two traits in aviation since they strongly impact training efficiency, performance, stress level, and coping ability.

In addition to the psychological and behavioral dimensions, the physiological responses depend also on personality traits, in particular when individuals are under pressure. This fact has been evidenced using diverse measures, such as heart rate variability [10], respiration rate [11], endocrine responses, noradrenaline [12] or cortisol levels [13], facial electromyography [14], or electroencephalography [15]. However, to our knowledge, psychological models gathering personality dimensions, cognitive demand and subjective feelings with physiology responses are scarcely proposed in the framework of safety research. Interestingly, in [16], the interactionist model of job performance is discussed. This model could lay the groundwork for theoretical approaches which could complement or nuance the findings from application driven studies, such as the present one.

Together with the analysis of the cardiovascular activity [17,18], the analysis of SCR is arguably a promising approach in aeronautics to determining the emotional state of pilots. This is due to its corroborated reliability in evaluating arousal and acute stress in different applications [19], to the point of even discriminating between stress and high cognitive workload [20], and to the easy acquisition of the electrodermal activity by wearable devices, including popular smartwatches. The SCR is the phasic component of the electrodermal activity signal and is constituted by the faster variations in the skin conductance, unlike the tonic component [21]. This physiological parameter, which is closely linked to arousal and stress, has been studied in different populations of pilots for various applications. For instance, in [22], the authors remark on the need for deeper analysis of SCR to determine the contribution of individual differences to understanding its links with affective patterns during soaring flying simulations. In [23], the value of SCR was used to estimate proneness to attentional tunneling according to the previous level of training in a simulator. Their results show that the more trained group showed not only better performance but also that they were less sensitive to stress as measured by the electrodermal activity. However, some works dealing with the physiological assessment of cognitive workload via SCR found an evident influence of inter-individual characteristics on the reliability of this feature [24,25]. Hence, these individual aspects are worthy of study.

Similarly to the other measures, the SCR is also influenced by personality factors [26]. In [27], an inferential model based on the electrodermal responses for detecting different psychological dimensions, including motivational aspects, temperament types, emotional intelligence, and personality traits, has been implemented. The authors notably ground their work on the findings from [26], which claims that electrodermal lability/stability can be considered as a psychophysiological index for individual differences in the effortful 
control of emotional manifestation. Higher lability would correspond to a greater cognitive effort to inhibit emotional expression. In the psychology of sport, [28] found that there is a positive correlation between conscientiousness and electrodermal stability in athletes one hour before competition.

As mentioned, the capacity of emotion regulation is crucial during a flight to guarantee safety, since pilots are facing numerous sources of stress. These sources could come not only from the inherent physical environment of their activity, such as noise, vibrations, turbulence, temperature variations [29], or unexpected events or systems failure etc., but also from individual psychological factors and external or personal situations. Further, high cognitive workload, caused by a complicated flight context (e.g., due to unfavorable weather conditions), or by multi-tasking (e.g., paying attention to air traffic control instructions and simultaneous information from the cockpit instruments), can also be a source of anxiety leading to deleterious effects on perception, attentional resource allocation, and subsequently on the pilot's performance [30]. Thus, studies in aeronautics motivate further research on these endogenous and exogenous sources of anxiety and stress, where individual differences are taken into account in experimental settings [31].

The goal of this study was twofold. Firstly, we intended to examine the link between pilots' personality trait scores and the anxiety generated by a flight simulation that included cognitive workload variations. According to findings in other contexts mentioned below, a positive correlation would be expected between anxiety and neuroticism, with an inverse pattern for conscientiousness (negative correlation between anxiety and conscientiousness). Secondly, we assessed whether pilots' personality traits correlate to SCR during the simulation. According to $[4,26]$, the more pronounced the features of directed impulse control personality (high neuroticism, low conscientiousness), the more the stability of electrodermal activity would be expected.

\section{Materials and Methods}

\subsection{Participants}

Twenty pilots (only men; age: $22.7 \pm 3.7$ years) recruited from the French Civil Aviation University (ENAC, Toulouse, France) participated in the study. We contacted all the available volunteers. They were all healthy without a history of grave medical treatment, with neither psychological nor psychiatric troubles. All participants had normal or corrected to normal vision, normal auditory acuity, and were fluent in English.

They all owned a Private Pilot License. At least 50 flight hours of flying experience was required $(M=141.3 \pm 139.5 \mathrm{~h})$, as was familiarity with flight simulations. All of them gave written informed consent $48 \mathrm{~h}$ before the experiment. The study was conducted in accordance with the guidelines of the Declaration of Helsinki, and approved by the Medical

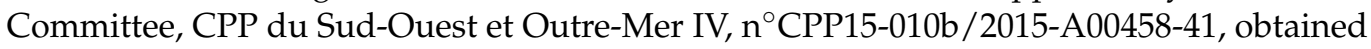
for the NEUROERGO project.

\subsection{Individual Differences Assessment}

\subsubsection{Personality Traits}

The participants completed the Neuroticism and Conscientiousness subscales of the BFI, previously used to assess pilot personality [3]. For both subscales, participants indicated how accurately 9 traits described them on a 5-point scale, ranging from 1 (very inaccurate) to 5 (very accurate). In order to obtain the final values, the responses associated with each trait were averaged. This questionnaire was completed before experimentation.

\subsubsection{Subjective Anxiety}

Given the stress inducement method employed in this study, based on the competition between participants (Section 2.2.4), and also given the possibility of estimating several dimensions of anxiety from a non-clinical standpoint, the Competition State Anxiety Inventory-2 (CSAI-2), [32] was chosen to quantify anxiety. Specifically, the CSAI-2R version revised by [33] was completed by participants in the middle of the experiment, between the 
control and the stress conditions to guarantee that the reported anxiety was associated with the induced stress after knowing that they would be evaluated. CSAI-2 has been utilized in different research works dealing with personality traits, [34,35]. It allows measuring the cognitive states of anxiety, somatic anxiety, and self-confidence.

\subsubsection{Experimental Setting and Procedure}

The experiment was carried out in an AL-50 flight simulator (CALSIM, France) and comprised two dual-task scenarios (2 levels of stress) that demanded the simultaneous performance of a flight plan and a secondary task. Within each dual-task scenario, two different levels of difficulty were manipulated (2 levels of cognitive workload as explained in Section 2.2.5).

Each flight scenario lasted nearly $35 \mathrm{~min}$ and both were equivalent in terms of difficulty and maneuvers, including take-off, cruise, and landing. Figure 1 shows an example of one of the scenarios. The instructions of the flight plan were accessible throughout the scenario on a blackboard in front of the simulator. Pilots had the opportunity to get familiar with the simulator some minutes before the experiments.

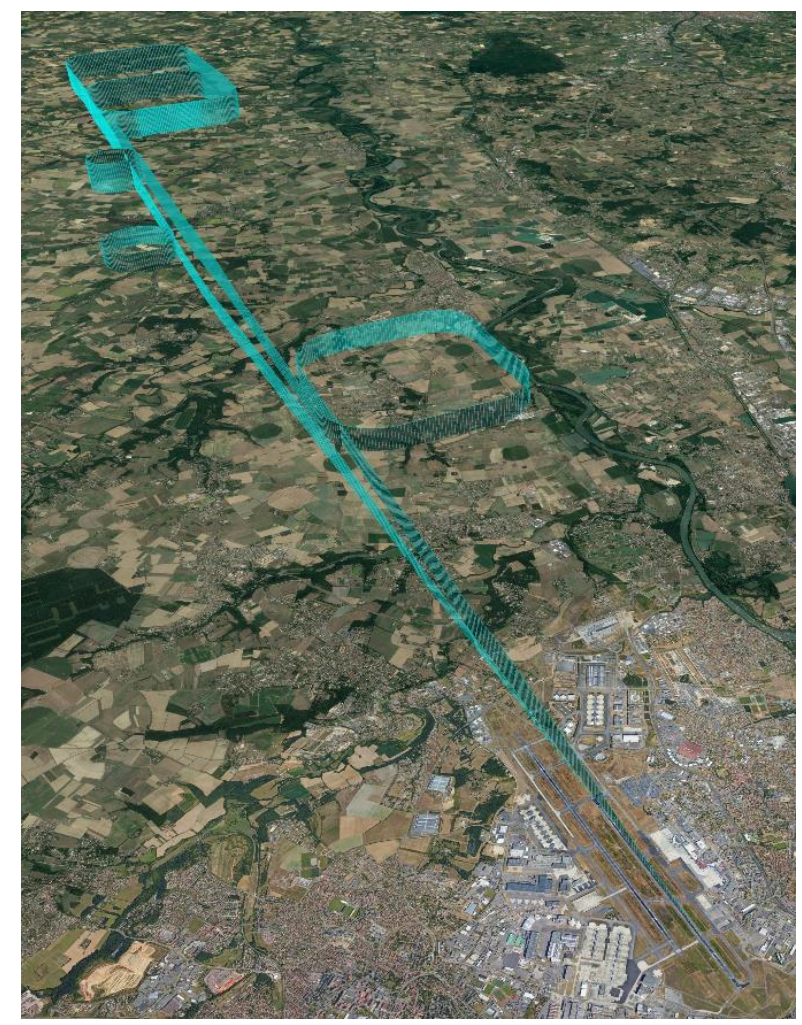

Figure 1. Flight scenario. The blue color indicates the trajectory that the participants had to follow.

\subsubsection{Stress Manipulation}

During the first scenario, which can be considered as the "no stress" condition or control condition, the pilots were alone. During the second scenario, the "stress" condition was generated by using the method utilized by [36]. More specifically, a pilot's emotional state was altered by a social stressor consisting of being filmed and evaluated by two researchers. The evaluation led the participants to compete with the others, as the results of this competition would be published online.

\subsubsection{Cognitive Workload Manipulation}

The secondary task consisted of pressing a 7" touch-screen, located next to the command panel, as rapidly as possible after hearing some numbers incorporated among some air traffic control instructions (unrelated to the flights but which improved the simulation 
immersion and served as a potential distractor to increase attentional demand). This secondary task was presented all along the cruise (duration = $12 \mathrm{~min}$ ) and was performed under two different levels of difficulty [18].

In the "Low Cognitive Workload" (LCW) condition, the participant was told to press the screen if the broadcasted numbers met one of two different possible attributes (either the number value was higher than 5 or its parity was even); in the "High Cognitive Workload" (HCW) condition, the quality (magnitude or parity) on which the participant attention had to be focused on depended on the color of the number displayed on the 7" touch-screen, which could be different to the heard number to make the task more difficult. Indeed, for the HCW condition, the participant was required to glance at the screen to check the color of the displayed number to know the specific attribute to consider for each heard number. This HCW condition required mental flexibility since the attribute to identify from the target number changed continuously.

The order in which each difficulty condition was performed in the dual-task scenarios was counterbalanced across participants.

\subsection{Data Acquisition and Processing}

\subsubsection{Physiological Data: Electrodermal Activity}

Electrodermal activity (EDA) was collected by means of two transducers placed on the hypothenar surface on the left hand (non-dominant hand for all the participants, except one). Galvanic Skin Response sensors were made by (Brain Products and the signal was recorded (sampling rate $=1 \mathrm{kHz}$ ) by the software BrainVision Recorder 1.21 (www.brainproducts.com, accessed on 16 June 2021). EDA signal processing was carried out by Ledalab toolbox (www.ledalab.de; v3.4.9, accessed on 16 June 2021) written in MATLAB ${ }^{\circledR}$.

A decomposition of EDA signals into tonic and phasic components was computed by a continuous decomposition analysis [37]. The parameters defining the EDA waves were proposed by Ledalab by default and the artefact rejection was automatically carried out by the same software to avoid noise contribution. An amplitude threshold of $0.05 \mu \mathrm{S}$ [21] was set to identify significant SCRs. Deflections in the signal lower than the amplitude threshold were not counted as SCRs. This threshold is often used in research works dealing with stress and arousal detection [38,39]. Deflections in the signal higher than the amplitude threshold during each condition (12 $\mathrm{min}$ ) were counted (to measure the total value of SCR). Due to technical issues, the physiological signals from three participants were not exploitable and their data were removed.

\subsubsection{Performance Measurements}

Specific timings for the flight instructions were demanded of participants. Different flight parameters were recorded to quantify flight performance. Speed (measured in knots), altitude (in meters) and heading (in degrees) were recorded during the flight simulations (sampling rate $=1 \mathrm{~Hz}$ ). The performance was considered satisfactory when the deviances of the parameters were not greater than \pm 5 units from the expected flight parameter. Deviances greater than \pm 5 units from the expected flight parameter were counted as errors.

The performance parameters were used to verify the proper realization of the flights to ensure that every participant carried out the simulation rigorously.

\subsection{Statistical Analysis}

Normality was confirmed by Shapiro-Wilk test. For self-reported anxiety analysis: Pearson's correlation coefficients were computed between each personality trait (conscientiousness, neuroticism) and both the CSAI-2R anxiety dimensions and the total values of SCR (for each condition). The analysis was completed with linear and quadratic regression analysis on the significant correlations. Overall, a statistical power of 0.92 was achieved. 
For electrodermal activity: repeated measures analysis of variance (ANOVA) were performed on the values of SCR. Two main factors were considered: the level of stress (no stress and stress) and the level of cognitive workload (LCW and HCW).

The personality traits (conscientiousness and neuroticism) were included as covariates one at a time due to the sample size $(N=17)$. Cronbach's $\alpha$ was computed on CSAI-2R and personality traits to verify the reliability of pre-defined dimensions and Guttman Split-Half coefficient for assessing SCR reliability, performed in R.

\section{Results}

3.1. Personality Traits (Conscientiousness and Neuroticism) and State Subjective Anxiety (CSAI-2R)

Table 1 shows the values for each personality trait and CSAI-2R anxiety dimensions. No significant correlation was found between the personality traits $(r=-0.337 ; p=0.186)$.

Table 1. Values of the features characterizing individual differences in the present study.

\begin{tabular}{cccccc}
\hline & Measure & Cronbach's $\alpha$ & Mean & [Min-Max] & $\begin{array}{c}\text { Std. } \\
\text { Deviation }\end{array}$ \\
\hline $\begin{array}{c}\text { Personality } \\
\left(\text { BFI }^{\mathrm{a}}\right)\end{array}$ & Conscientiousness & 0.885 & 3.96 & {$[2.89-5.00]$} & 0.675 \\
\hline Nnxiety & Couroticism & 0.773 & 1.89 & {$[1.13-2.88]$} & 0.450 \\
\hline$\left(\right.$ CSAI-2R $\left.{ }^{\mathrm{b}}\right)$ & Somitive anxiety & 0.950 & 12.24 & {$[7-25]$} & 5.663 \\
& Self confidence & 0.813 & 11.64 & {$[7-18]$} & 3.517 \\
\hline
\end{tabular}

a Big Five Inventory; ${ }^{b}$ Competitive State Anxiety Inventory Revised.

Significant Pearson's correlations were found between neuroticism and the three anxiety dimensions of the CSAI-2R: cognitive anxiety $(r=0.721 ; p=0.001)$, somatic anxiety $(r=0.709 ; p=0.001)$ and self-esteem $(r=-0.627 ; p=0.007)$. The regression analysis showed a better fitting for quadratic curves mainly for the two first dimensions: cognitive anxiety $\left(R^{2}=0.550\right)$ and somatic anxiety $\left(R^{2}=0.528\right)$ as depicted in Figure $2,\left(R^{2}=0.397\right.$, for self-confidence). No significant correlation was found between conscientiousness and the three anxiety dimension levels: cognitive anxiety $(r=-0.082 ; p=0.755)$, somatic anxiety $(r=-0.326 ; p=0.202)$ and self-esteem $(r=-0.404 ; p=0.108)$.

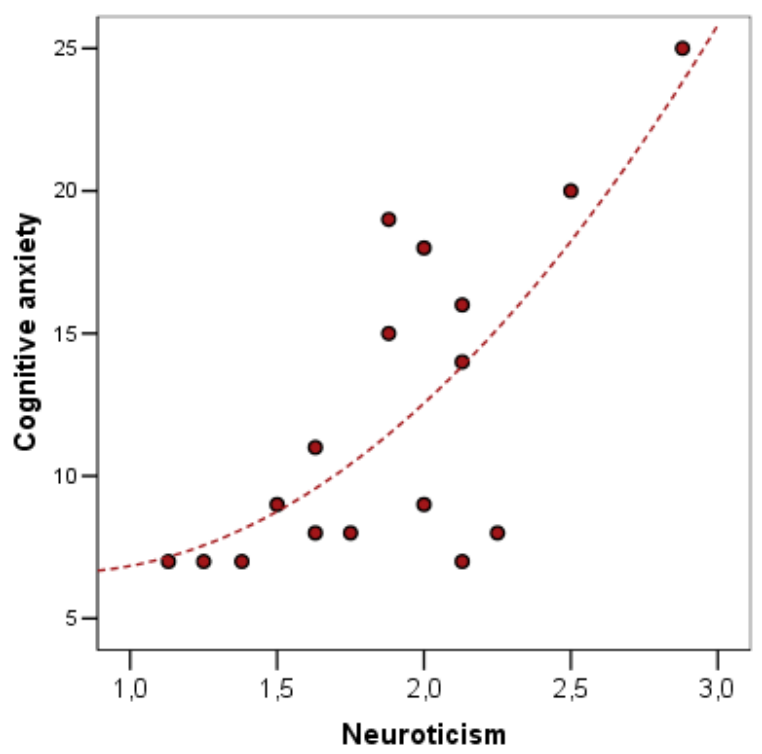

(a)

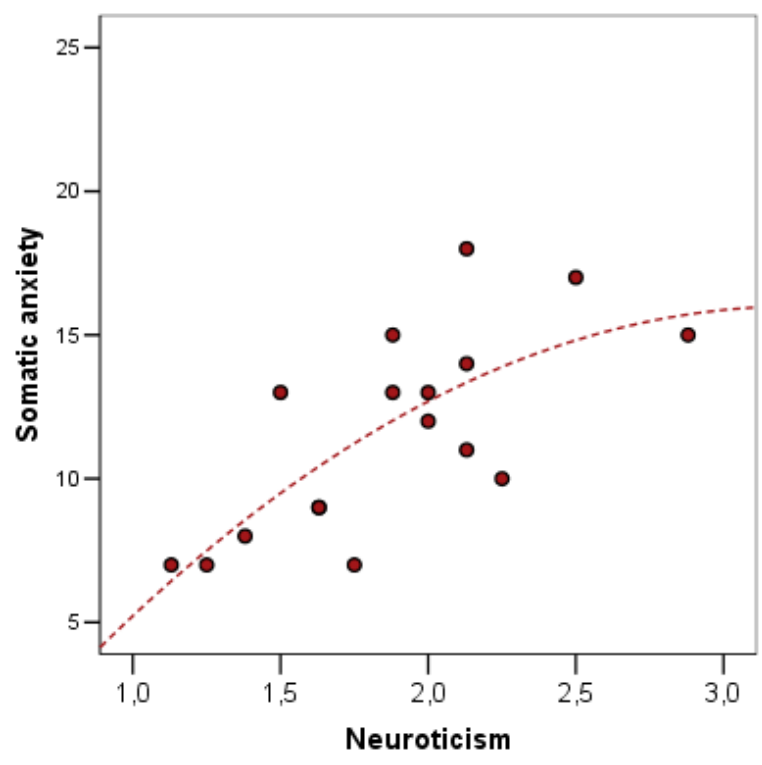

(b)

Figure 2. Relation between neuroticism level (measured with the BFI) and: (a) cognitive anxiety; (b) somatic anxiety (measured with the CSAI-2R). 
No significant correlation was found between anxiety and flight performances. A study of the impact of cognitive workload on performance can be found in [40].

\subsection{Personality Traits (Conscientiousness and Neuroticism) and Physiology (SCR)}

When conscientiousness value was included as a covariate in the ANOVA, a significant main effect of stress was found on SCR, $\mathrm{F}(1,15)=10.93 ; p=0.005 ; \eta_{\mathrm{p}}{ }^{2}=0.421$, leading to a higher value of SCR for the "stress" conditions ( $M=242 \pm 56$ for LCW; $M=234 \pm 63$ for HCW) than for the "no stress" conditions ( $M=215 \pm 46$ for LCW; $M=213 \pm 44$ for HCW). The interaction between stress and conscientiousness, $\mathrm{F}(1,15)=9.39 ; p=0.008 ; \eta_{\mathrm{p}}{ }^{2}=0.385$, and a between-subject effect of conscientiousness was also significant, $F(1,15)=4.51$; $p=0.05 ; \eta_{\mathrm{p}}^{2}=0.231$.

Indeed, significant correlations were found between conscientiousness and the value of SCR for both LCW ( $r=-0.675 ; p=0.003)$ and HCW $(r=-0.654 ; p=0.004)$ under "stress" conditions. Figure 3 depicts both scatterplots with the linear curve fit. No significant differences in SCR were found between LCW and HCW. No significant correlations between conscientiousness and SCR were found for the "no stress" condition.

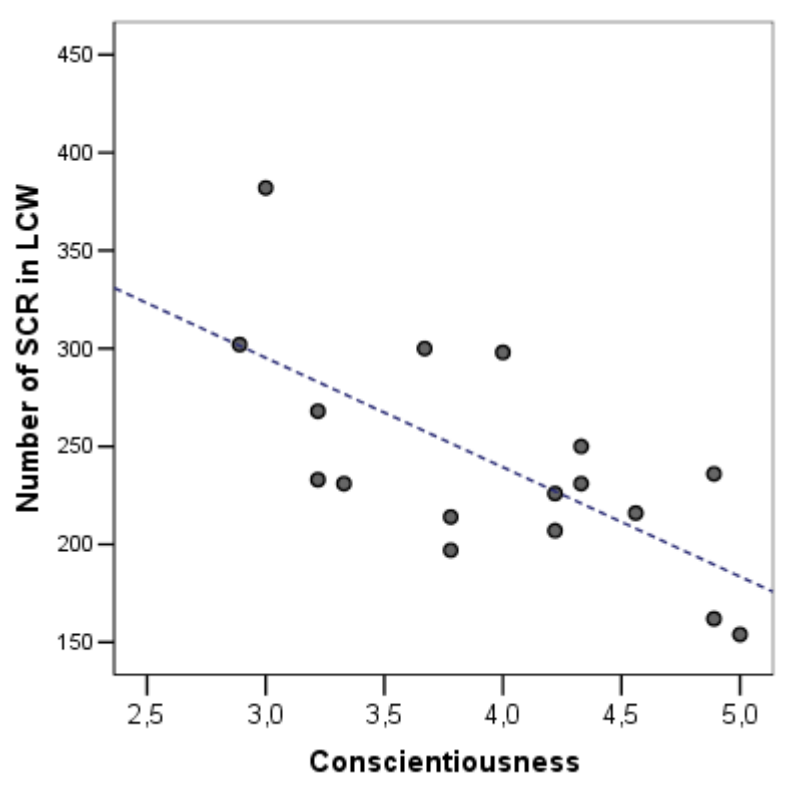

(a)

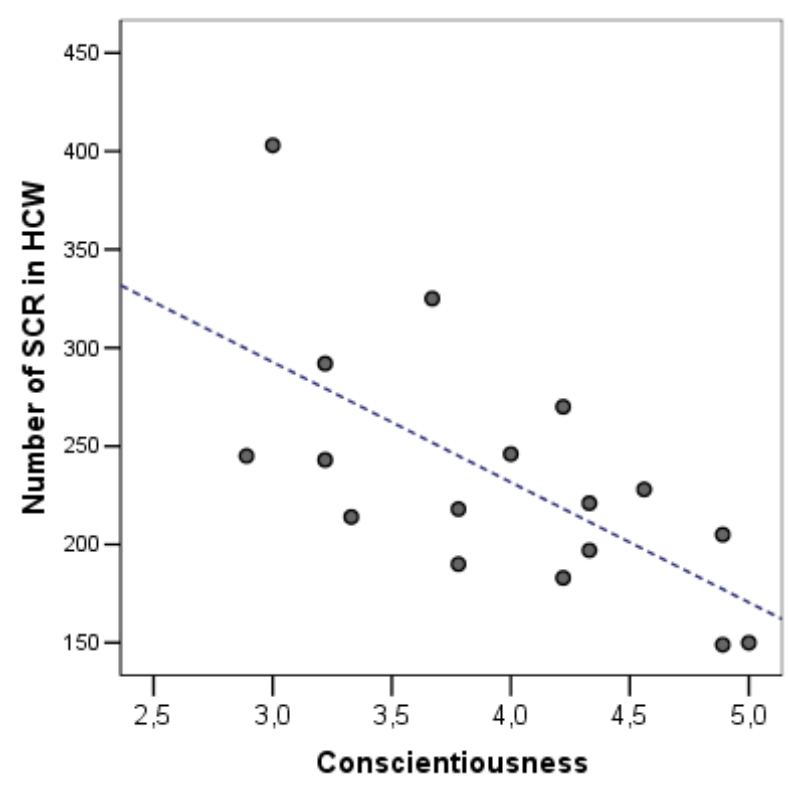

(b)

Figure 3. Relation between the number of phasic skin conductance responses SCR under stressful condition and conscientiousness for: (a) low cognitive workload (LCW); (b) high cognitive workload (HCW).

Regarding neuroticism, when it was included as a covariate in the ANOVA, the effect of the trait was not significant $(p=0.33)$. Correlations between neuroticism with any condition were not significant.

Finally, no significant correlations were found between the value of SCR and the anxiety scores from CSAI-2R.

The reliability estimate for SCR (Split-Half method) was $r=0.83 ; 95 \%$ CI $=[0.68,0.96]$.

\section{Discussion}

This study examined the individual differences in pilots concerning not only their personality style, but also the links of their variations to subjective feelings of anxiety and the subsequent impact on the physiological responses, specifically on the skin responses (SCR) during complex and stressful flight simulations. To our knowledge, this is the first study simultaneously considering personality, self-reported anxiety, and physiological correlates while carrying out a dual-task flight scenario under a social stressor. This type of 
study has been mainly carried out on athlete populations, but their specific profiles might not lead to the same conclusions as with pilots.

The main results were, on the one hand, the positive relation between neuroticism and anxiety intensity (for its cognitive and the somatic expressions); on the other hand, the positive relation between electrodermal stability and conscientiousness level when pilots were placed in stressful conditions (social stressor). The results are discussed in more detail below.

\subsection{Neuroticism Level Modulates Subjective Anxiety in Pilots}

The neuroticism and conscientiousness levels of the pilots participating in the present research are in line with other findings in the literature, although more experienced pilots [3] or military pilots [41] were considered in these two latter studies. A higher level of conscientiousness and a lower level of neuroticism were found (Table 1) in comparison to the general population according to the findings of [3]. A priori, this outcome may reflect a trend of this specific population toward demonstrating a strong motivation towards the proper completion of goals [4], e.g., flight plans and simultaneous cognitive tasks in this study, and a weak tendency to anxiety under pressure. In any case, it is crucial to take into consideration individual reactions to stressful situations in aviation, since they can lead to poorer performance [40,42].

Even when neuroticism scores were moderate, a positive correlation with the subjective anxiety felt by pilots was found while they were carrying out the tasks under the social stressor. This correlation was shown in the literature in very different situations where a social evaluation was present. For instance, [43] found that neuroticism and trait anxiety was predictive of music performance anxiety. Furthermore, [34] found similar results regarding neuroticism and the CSAI dimensions in an athlete population. According to our results, the relation was rather quadratic. A more pronounced increase for cognitive anxiety than for somatic anxiety was found. The effect of a social stressor such as the presence of an evaluator was proven to generate higher levels of cognitive anxiety in a similar protocol used by [36], who linked it to the ego-threatening instructions. This feeling of threat would be more important in people scoring higher in neuroticism since they are more sensitive to negativity and consequently to the possible mistakes they could make. For somatic anxiety, the increase was less pronounced in the highest levels of neuroticism due to the quadratic relation. Note that the questionnaire about anxiety was completed before the flight and probably the physiological stress reactions were not yet completely triggered. Finally, the results on self-confidence in pilots are in agreement with previous findings in the general population. In the literature, it is suggested that self-esteem or self-confidence and neuroticism could represent the same construct [44] as well as self-efficacy, which can be enhanced in competition contexts.

Regarding conscientiousness, some research works found a negative relation with perceived stress [45]. However, this result was not confirmed in our population. This non-result was also found by [34], maybe due to other personality traits or to the mediating effect of self-efficacy, as [45] found. Given the link between conscientiousness and perfectionism [9], any correlation sign could be expected. On one side, the pilots worried about making an excellent performance could feel stressed as they would not want to disappoint. Arguably, to determine the influence of conscientiousness on subjective anxiety, it could be convenient to make clusters with the neuroticism level to study the personality style separately in studies with a higher number of participants as hinted by [4].

\subsection{Conscientiousness Correlates with Electrodermal Stability}

Interestingly, conscientiousness showed a significant negative correlation with the value of SCR, or, in other words, higher scores in conscientiousness were linked to more stable EDA signals. This result is in agreement with [26] regarding skin reactions to stress mediated by personality. Usually, conscientiousness is related to concentration on a task, so pilots with higher scores of this personality trait are probably able to keep their attention 
focused on the flight task, independently of the presence of a secondary task and external stressors, as suggested in [18]. In this way, they could feel rather a positive stress or eustress [46], which would make the physiological responses more stable, with a lower number of relevant peaks. This fact may suggest that monitoring systems for determining the emotional state of the operators might be more reliable in individuals scoring higher in conscientiousness. Analogously to the conclusions drawn from the subjective anxiety, the study of personality could benefit from the clustering of several personality traits, and specifically of the two traits included in this study. No difference in the value of SCR was found when cognitive workload increased. This fact may suggest that the level of conscientiousness affects the physiological expression of the stress elicited by external stimuli instead of the stress proceeding from cognitive demands.

According to the results discussed in the previous section and from the experiments by [34], carried out with athletes before a competition, a negative correlation could be expected between EDA stability and neuroticism as far as the subjective anxiety was linked to physiological activation. On the contrary, no significant correlation was found between neuroticism and the value of SCR in our study. In the analysis of [34], the global EDA was considered without decomposing the signal into phasic and tonic responses. Neuroticism could be rather linked to the acute reactions to negative stimuli and therefore be more impacted by other kinds of stressors (other than social evaluation) or emotional states, such as sadness [14] and consequently be more sensitive to amplitude values. In any case, note that cognitive anxiety presented higher scores than somatic anxiety. The latter could be more directly related to physiological responses. However, this is not the first time that no correlation was found between objective physiological activity and cognitive anxiety. Indeed, in [47], the authors found a stronger association between respiration rate and somatic anxiety instead of cognitive anxiety in archers with the highest level of neuroticism. Hence, the low scores on neuroticism, though correlated with anxiety level, were not elevated enough to enhance EDA lability, contrary to the findings of other research [26].

\subsection{Limitations of the Study}

The present study has some limitations that force us to be cautious when drawing conclusions. Firstly, although the cognitive workload conditions (LCW and HCW) were counterbalanced within each dual-task scenario, the stress condition was always after the control (no stress) condition. This choice was made to prevent the persistence of a negative mood for the subsequent control condition. An eventual influence of the fatigue or a slight degradation of the EDA signals cannot be completely discarded.

As pointed out by other research works, the inducing of stress in a flight simulator differs qualitatively from the possible stressors in real conditions. Besides, the dual task performed by the participant showed a limited ecological value.

A greater sample size would have been desirable in order to draw more generalizable conclusions. With a greater sample size, other personality traits (e.g., agreeableness or openness) could have been added and clustered to find out their influence. Furthermore, the conclusions of the present study may only be extrapolated to male pilots due to the available sample. Future research could aim to include female pilots to determine gender differences.

\section{Conclusions and Perspectives}

This work shows two main results. Firstly, it shows a positive relation between neuroticism and anxiety. Secondly, it shows a positive relation between conscientiousness and SCR stability. A pilot capable of keeping higher concentration levels during stressful flight situations will present a more stable SCR during other stressful situations, such as a supervised simulation. In addition, the calibration for the online monitoring should take this into account, using lower SCR stress detection thresholds for pilots with higher conscientiousness. Future studies could also incorporate other robust measures of personality, 
such as the MMPI-2, which may also modulate psychophysiological responses, such as SCR [48].

Furthermore, these results can have applications not only for tailoring the monitoring systems of internal state of pilots to determine their actual capacity to cope with stress in risky situations, but also for pilot selection. Indeed, response distortion is a concern in personality measurement by subjective questionnaires, especially in high stake contexts, e.g., in [49]. Actually, it may lead to inflated scores on socially desirable items and decrease the validity of the personality trait scores. In a context of pilot selection, one may expect, for instance, that applicants inflate conscientiousness score. The present study highlighted a relationship between physiological responses in a stressful situation and the self-assessment of conscientiousness. Thus, one may imagine using physiological measurements during the selection process, while applicants perform a stressful task, and infer personality trait characteristics from them. As physiological responses rely on uncontrolled processes, one could hypothesize that faking would be more difficult. In any case, these applications could benefit from other more fundamental studies based, for instance, on mediation or moderation models describing the interaction between personality profiles and physiology.

Author Contributions: Conceptualization, A.R.H.-M., R.E.-Y. and N.M.; methodology, A.R.H.-M., D.M., R.E.-Y. and N.M.; software, D.M. and Y.R.; validation, A.R.H.-M., R.E.-Y., N.M. and M.C.; formal analysis, A.R.H.-M. and D.M.; resources, R.E.-Y. and N.M.; writing—original draft preparation, A.R.H.-M.; writing-review and editing, N.M. and M.C.; visualization, A.R.H.-M. and D.M.; project administration, M.C. All authors have read and agreed to the published version of the manuscript.

Funding: This work was supported by the French Research National Agency (ANR) and the French Defense Procurement Agency (DGA) via the Accompagnement Spécifique des travaux de Recherches et d'Innovation Défense (ASTRID), project research “NEUROERGO”, grant number ANR-13-ASTR-0036. The APC was funded by CASAC chair granted from Dassault Aviation through ISAE-SUPAERO Foundation.

Institutional Review Board Statement: The study was conducted according to the guidelines of the Declaration of Helsinki, and approved by medical Committee, CPP du Sud-Ouest et Outre-Mer IV, $\mathrm{n}^{\circ} \mathrm{CPP} 15-010 \mathrm{~b} / 2015-\mathrm{A00458-41}$, obtained for the NEUROERGO project.

Informed Consent Statement: Informed consent was obtained from all subjects involved in the study this paper.

Data Availability Statement: The data presented in this study are available on request from the corresponding author. The data are not publicly available due to confidential issues.

Acknowledgments: Anne Henric, Head of Air Transport Department at ENAC, who enabled access to the simulator for data collection.

Conflicts of Interest: The authors declare no conflict of interest.

\section{References}

1. Stokes, A.F.; Kite, K. Flight Stress: Stress, Fatigue and Performance in Aviation; Routledge: London, UK, 2017; ISBN 1-351-93634-4.

2. Costa, P.T.; McCrae, R.R. The NEO Personality Inventory; Psychological Assessment Resources: Odessa, FL, USA, 1985.

3. Fitzgibbons, A.; Davis, D.; Schutte, P.C. Pilot Personality Profile Using the NEO-PI-R; National Aeronautics and Space Administration, Langely Research Center: Hampton, VA, USA, 2004.

4. Weiss, A.; Sutin, A.R.; Duberstein, P.R.; Friedman, B.; Bagby, R.M.; Costa, P.T., Jr. The Personality Domains and Styles of the Five-Factor Model Are Related to Incident Depression in Medicare Recipients Aged 65 to 100. Am. J. Geriatr. Psychiatry 2009, 17, 591-601. [CrossRef]

5. Vollrath, M.; Torgersen, S. Who Takes Health Risks? A Probe into Eight Personality Types. Personal. Individ. Differ. 2002, 32, 1185-1197. [CrossRef]

6. Penley, J.A.; Tomaka, J. Associations among the Big Five, Emotional Responses, and Coping with Acute Stress. Personal. Individ. Differ. 2002, 32, 1215-1228. [CrossRef]

7. Bishop, S.; Forster, S. Trait Anxiety, Neuroticism, and the Brain Basis of Vulnerability to Affective Disorder. In The Cambridge Handbook of Human Affective Neuroscience; Armony, J., Vuilleumier, P., Eds.; Cambridge University Press: Cambridge, UK, 2013; pp. 553-574. 
8. Studer-Luethi, B.; Jaeggi, S.M.; Buschkuehl, M.; Perrig, W.J. Influence of Neuroticism and Conscientiousness on Working Memory Training Outcome. Personal. Individ. Differ. 2012, 53, 44-49. [CrossRef]

9. Stoeber, J.; Otto, K.; Dalbert, C. Perfectionism and the Big Five: Conscientiousness Predicts Longitudinal Increases in Self-Oriented Perfectionism. Personal. Individ. Differ. 2009, 47, 363-368. [CrossRef]

10. Shepherd, D.; Mulgrew, J.; Hautus, M.J. Exploring the Autonomic Correlates of Personality. Auton. Neurosci. 2015, 193, 127-131. [CrossRef]

11. Stemmler, G.; Wacker, J. Personality, Emotion, and Individual Differences in Physiological Responses. Biol. Psychol. 2010, 84, 541-551. [CrossRef] [PubMed]

12. LeBlanc, J.; Ducharme, M.; Thompson, M. Study on the Correlation of the Autonomic Nervous System Responses to a Stressor of High Discomfort with Personality Traits. Physiol. Behav. 2004, 82, 647-652. [CrossRef]

13. Bibbey, A.; Carroll, D.; Roseboom, T.J.; Phillips, A.C.; de Rooij, S.R. Personality and Physiological Reactions to Acute Psychological Stress. Int. J. Psychophysiol. 2013, 90, 28-36. [CrossRef]

14. Steenhaut, P.; Demeyer, I.; De Raedt, R.; Rossi, G. The Role of Personality in the Assessment of Subjective and Physiological Emotional Reactivity: A Comparison between Younger and Older Adults. Assessment 2018, 25, 285-301. [CrossRef]

15. Hidalgo-Muñoz, A.R.; Pereira, A.T.; López, M.M.; Galvao-Carmona, A.; Tomé, A.M.; Vázquez-Marrufo, M.; Santos, I.M. Individual EEG Differences in Affective Valence Processing in Women with Low and High Neuroticism. Clin. Neurophysiol. 2013, 124, 1798-1806. [CrossRef]

16. Tett, R.P.; Burnett, D.D. A Personality Trait-Based Interactionist Model of Job Performance. J. Appl. Psychol. 2003, 88, 500. [CrossRef] [PubMed]

17. Causse, M.; Dehais, F.; Faaland, P.-O.; Cauchard, F. An Analysis of Mental Workload and Psychological Stress in Pilots during Actual Flight Using Heart Rate and Subjective Measurements. In Proceedings of the 5th International Conference on Research in Air Transportation (ICRAT 2012), Barkely, CA, USA, 22-25 May 2012.

18. Hidalgo-Muñoz, A.R.; Mouratille, D.; Matton, N.; Causse, M.; Rouillard, Y.; El-Yagoubi, R. Cardiovascular Correlates of Emotional State, Cognitive Workload and Time-on-Task Effect during a Realistic Flight Simulation. Int. J. Psychophysiol. 2018, 128, 62-69. [CrossRef] [PubMed]

19. Boucsein, W. Electrodermal Activity; Springer Science \& Business Media: New York, NY, USA, 2012; ISBN 1-4614-1126-2.

20. Setz, C.; Arnrich, B.; Schumm, J.; La Marca, R.; Tröster, G.; Ehlert, U. Discriminating Stress from Cognitive Load Using a Wearable EDA Device. IEEE Trans. Inf. Technol. Biomed. 2009, 14, 410-417. [CrossRef] [PubMed]

21. Braithwaite, J.J.; Watson, D.G.; Jones, R.; Rowe, M. A Guide for Analysing Electrodermal Activity (EDA) \& Skin Conductance Responses (SCRs) for Psychological Experiments. Psychophysiology 2013, 49, 1017-1034.

22. Moon, S.M.; Qu, Y. A Quantitative Approach for Determining Pilot Affective Patterns during Soaring Flight Simulation; IEEE: Toulouse, France, 2017; pp. 2617-2624.

23. Koglbauer, I.; Kallus, K.W.; Braunstingl, R.; Boucsein, W. Recovery Training in Simulator Improves Performance and Psychophysiological State of Pilots during Simulated and Real Visual Flight Rules Flight. Int. J. Aviat. Psychol. 2011, 21, 307-324. [CrossRef]

24. Gaetan, S.; Dousset, E.; Marqueste, T.; Bringoux, L.; Bourdin, C.; Vercher, J.-L.; Besson, P. Cognitive Workload and Psychophysiological Parameters during Multitask Activity in Helicopter Pilots. Aerosp. Med. Hum. Perform. 2015, 86, 1052-1057. [CrossRef]

25. Lassalle, J.; Rauffet, P.; Leroy, B.; Guillet, L.; Chauvin, C.; Coppin, G. Innovative Multi-Sensors Device Deployment for Fighter Pilots Activity Study in a Highly Realistic Rafale Simulator. In Proceedings of the Human Factors and Ergonomics Society Europe Chapter 2014 Annaual Conference, Lisbon, Portugal, 8-10 October 2014. Available online: http:/ / hfes-europe.org (accessed on 18 June 2021).

26. Crider, A. Personality and Electrodermal Response Lability: An Interpretation. Appl. Psychophysiol. Biofeedback 2008, 33, 141-148. [CrossRef]

27. Zaharia, C.M.; Grigore, D.; Moldovan, M. Determining Personality Profile through Inferential Method by EDA Neurosignals. Sci. Res. Educ. Air Force AFASES 2017, 2, 241-256. [CrossRef]

28. Binboga, E.; Guven, S.; Çatıkkaş, F.; Bayazıt, O.; Tok, S. Psychophysiological Responses to Competition and the Big Five Personality Traits. J. Hum. Kinet. 2012, 33, 187-194. [CrossRef] [PubMed]

29. Blogut, A. Stressing Factors in Aviation. Sci. Res. Educ. Air Force AFASES 2015, 1, 165-170.

30. Mandrick, K.; Peysakhovich, V.; Rémy, F.; Lepron, E.; Causse, M. Neural and Psychophysiological Correlates of Human Performance under Stress and High Mental Workload. Biol. Psychol. 2016, 121, 62-73. [CrossRef]

31. Sehlström, M. Personality and Stress in Simulated Aviation Training (Dissertation). 2018. Available online: http://urn.kb.se/ resolve?urn=urn:nbn:se:umn:diva-149068 (accessed on 18 June 2021).

32. Martens, R.; Vealey, R.S.; Burton, D. Competitive Anxiety in Sport; Human Kinetics Books: Champaign, IL, USA, 1990.

33. Martinent, G.; Ferrand, C.; Guillet, E.; Gautheur, S. Validation of the French Version of the Competitive State Anxiety Inventory-2 Revised (CSAI-2R) Including Frequency and Direction Scales. Psychol. Sport Exerc. 2010, 11, 51-57. [CrossRef]

34. Balyan, K.Y.; Tok, S.; Tatar, A.; Binboga, E.; Balyan, M. The Relationship among Personality, Cognitive Anxiety, Somatic Anxiety, Physiological Arousal, and Performance in Male Athletes. J. Clin. Sport Psychol. 2016, 10, 48-58. [CrossRef]

35. Laborde, S.; Lautenbach, F.; Allen, M.S.; Herbert, C.; Achtzehn, S. The Role of Trait Emotional Intelligence in Emotion Regulation and Performance under Pressure. Personal. Individ. Differ. 2014, 57, 43-47. [CrossRef] 
36. Allsop, J.; Gray, R. Flying under Pressure: Effects of Anxiety on Attention and Gaze Behavior in Aviation. J. Appl. Res. Mem. Cogn. 2014, 3, 63-71. [CrossRef]

37. Benedek, M.; Kaernbach, C. Decomposition of Skin Conductance Data by Means of Nonnegative Deconvolution. Psychophysiology 2010, 47, 647-658. [CrossRef]

38. Pakarinen, T.; Pietilä, J.; Nieminen, H. Prediction of Self-Perceived Stress and Arousal Based on Electrodermal Activity; IEEE: Toulouse, France, 2019; pp. 2191-2195.

39. Hernandez, J.; Morris, R.R.; Picard, R.W. Call Center Stress Recognition with Person-Specific Models; Springer: Berlin/Heidelberg, Germany, 2011; pp. 125-134.

40. Hidalgo-Munoz, A.R.; Mouratille, D.; Rouillard, Y.; Matton, N.; Causse, M.; Yagoubi, R.E. Influence of Anxiety and Mental Workload on Flight Performance in a Flight Simulator. In Proceedings of the ICCAS 2020 1st International Conference on Cognitive Aircraft Systems, Toulouse, France, 18-19 March 2020.

41. Glicksohn, J.; Naor-Ziv, R. Personality Profiling of Pilots: Traits and Cognitive Style. Int. J. Personal. Psychol. 2016, 2, 7-14.

42. Vine, S.J.; Uiga, L.; Lavric, A.; Moore, L.J.; Tsaneva-Atanasova, K.; Wilson, M.R. Individual Reactions to Stress Predict Performance during a Critical Aviation Incident. Anxiety Stress Coping 2015, 28, 467-477. [CrossRef]

43. Smith, A.J.; Rickard, N.S. Prediction of Music Performance Anxiety via Personality and Trait Anxiety in Young Musicians. Aust. J. Music Educ. 2004, 1, 1-32.

44. Judge, T.A.; Erez, A.; Bono, J.E.; Thoresen, C.J. Are Measures of Self-Esteem, Neuroticism, Locus of Control, and Generalized Self-Efficacy Indicators of a Common Core Construct? J. Pers. Soc. Psychol. 2002, 83, 693. [CrossRef] [PubMed]

45. Ebstrup, J.F.; Eplov, L.F.; Pisinger, C.; Jørgensen, T. Association between the Five Factor Personality Traits and Perceived Stress: Is the Effect Mediated by General Self-Efficacy? Anxiety Stress Coping 2011, 24, 407-419. [CrossRef] [PubMed]

46. Le Fevre, M.; Matheny, J.; Kolt, G.S. Eustress, Distress, and Interpretation in Occupational Stress. J. Manag. Psychol. 2003, 18, 726-744. [CrossRef]

47. Dal, N.; Tok, S.; Dogan, E.; Balikçi, I.; Zekioglu, A.; Çatikkas, F. Somatic Anxiety May Represent Archers' Actual Autonomic Nervous System Activity but How: Moderating Role of Personality Traits. Univers. J. Educ. Res. 2018, 6, 1831-1836. [CrossRef]

48. McCord, D.M.; Achee, M.C.; Cannon, E.M.; Harrop, T.M.; Poynter, W.D. Using the Research Domain Criteria Framework to Explore Associations between MMPI-2-RF Constructs and Physiological Variables Assessed by Eye-Tracker Technology. J. Pers. Assess. 2017, 99, 363-374. [CrossRef]

49. Cao, M.; Drasgow, F. Does Forcing Reduce Faking? A Meta-Analytic Review of Forced-Choice Personality Measures in HighStakes Situations. J. Appl. Psychol. 2019, 104, 1347. [CrossRef] 